PALABRAS CLAVE

Mercosur

Integración económica Inversión extranjera directa Empresas transnacionales Movimientos de capital Exportaciones Importaciones Desarrollo económico América Latina

Daniel Chudnovsky

(1944-2007)

Fue Director del Centro de Investigaciones para la Transformación (CENIT) y Profesor de las Universidades de San Andrés y Buenos Aires

Andrés López

Director del CENIT y

Profesor de la Universidad

de Buenos Aires

• Anlopez@fund-cenit.org.ar
REVISTA DE LA CEPAL 92 • AGOSTO 2007

\section{Inversión extranjera directa y desarrollo: la experiencia del Mercosur}

\author{
Daniel Chudnorsky y Andrés López
}

$\mathrm{E}$

ste trabajo analiza los efectos de la inversión extranjera directa (IED) sobre los países del Mercosur, considerando variables clave como productividad, comercio exterior, innovación y crecimiento. Los efectos macroeconómicos no fueron significativos, en tanto que los microeconómicos parecen haber sido más fuertes, aunque heterogéneos. En general, las filiales de empresas transnacionales tienen mayor productividad, comercian más y son más innovadoras que las empresas locales. Los efectos indirectos de la IED, en cambio, son menos nítidos. El signo y la magnitud de los derrames de productividad hacia los competidores locales son heterogéneos y parecen depender de las características de estos últimos y de los mercados en que operan. Finalmente, solo en Brasil se encuentra evidencia de derrames - aunque tanto positivos como negativos - hacia las actividades de exportación e innovación de las empresas locales, así como derrames de productividad de las filiales extranjeras hacia sus proveedores nacionales. 


\section{I}

\section{Introducción}

Desde que se creó, el Mercosur ha sido uno de los principales focos de atracción de inversión extranjera directa (IED) dentro del grupo de los países en desarrollo. Entre 1990 y 2004 este bloque recibió IED por casi 300.000 millones de dólares.

De hecho, ya desde su período agroexportador Argentina y Brasil adoptaron estilos de desarrollo en los cuales la IED desempeñó un papel muy importante. Este papel se reforzó durante la fase final de la industrialización mediante sustitución de importaciones — desde mediados de los años 1950 hasta los 1970—, cuando las empresas extranjeras, junto con las de capital estatal, lideraron en ambos países el tránsito hacia industrias que hacen uso intensivo de capital y tecnología.

Si bien en los años 1980, como consecuencia de las profundas dificultades macroeconómicas por las que atravesó la región, las corrientes de IED declinaron apreciablemente, en la década siguiente el mejoramiento del clima macroeconómico contribuyó a que las corrientes de inversión se recuperaran y la región participara activamente del auge mundial de IED. Sin embargo, el contexto en el cual se dio este renovado interés de las empresas transnacionales por invertir en Argentina y Brasil fue muy distinto al vigente en la época de la industrialización sustitutiva de las importaciones.

En primer lugar, en los años 1990 se profundizó el proceso de globalización, con la creciente interdependencia de los países por la fuerte expansión de las corrientes internacionales de comercio, inversiones y tecnología; la consolidación de la tendencia a generar disciplinas internacionales en diversas áreas - fundamentalmente dentro de la Organización Mundial del Comercio (OMC) pero no solo en ella, y la proliferación de diversas

\footnotetext{
$\square$ Este trabajo emanó de un proyecto de investigación financiado por el International Development Research Centre (IDRC) en el marco de la Red Mercosur. Se agradecen los valiosos comentarios de Gustavo Bittencourt, Rosario Domingo, Celio Hiratuka y Mariano Laplane, así como las contribuciones de Eugenia Orlicki y la asistencia de Mara Pedrazzoli. Este proceso fue facilitado tanto por la mayor liberalización de las corrientes de comercio e inversión, como por la rápida difusión de las tecnologías de la información y las comunicaciones, que favorecen justamente la interconexión entre las diversas unidades de negocios de cada empresa, y entre dichas unidades y sus subcontratistas, proveedores y clientes.
}

formas de acuerdos binacionales o plurinacionales que van desde procesos de integración regional a tratados de inversión.

El gran auge de la IED en los años 1990 fue parte esencial de la globalización. En el año 2000 se llegó a una cifra record de 1.400 .000 millones de IED a nivel mundial, y si bien luego los flujos de inversión cayeron bruscamente, de todos modos todavía hoy superan con creces los promedios de las últimas décadas. $\mathrm{Al}$ mismo tiempo se incrementó el número de empresas transnacionales: mientras que a comienzos de los años 1990 se estimaba que existían alrededor de 37.000, con al menos 170.000 filiales extranjeras, en el 2004 estas empresa aumentaron a cerca de 70.000 , y sus filiales extranjeras a 690.000; casi la mitad de estas filiales se hallan en países en desarrollo (UNCTAD, 2005).

En ese marco, las propias estrategias de las empresas transnacionales se fueron transformando, tendiendo a constituir sistemas internacionales integrados de producción.

En segundo lugar, por el lado de las economías receptoras del Mercosur, el cambio fundamental fue el paso desde una economía semicerrada con fuerte presencia estatal, característica de la industrialización sustitutiva de las importaciones, a la adopción de reformas estructurales inspiradas en gran medida en el llamado Consenso de Washington. Estas tendían a abrir la economía y reducir el peso del Estado, proceso que tuvo su expresión más clara en términos de profundidad y rapidez de las reformas en el caso argentino.

El cambio de escenario local e internacional, combinado con las nuevas tendencias en las estrategias de las empresas transnacionales, debería haber dado lugar a transformaciones importantes en la dinámica de la IED en el Mercosur. En teoría, tendríamos que haber esperado no solo un cambio de los objetivos de las empresas transnacionales que invierten en la región, sino también de la forma en que organizan la actividad de sus filiales: mientras que en la época de la industrialización basada en la sustitución de importaciones la IED buscaba primordialmente explotar el acceso a los mercados internos protegidos, para lo cual se efectuaban inversiones en filiales poco articuladas con el resto de las actividades de la empresa, en los años 1990 la IED debería haber estado mucho más orientada al comercio 
internacional, incorporando más en las filiales locales la lógica de las cadenas productivas propias de cada empresa transnacional.

Asimismo, los efectos de la IED deberían ser distintos. Durante la industrialización sustitutiva, las empresas transnacionales exhibían niveles de productividad más altos que los de las empresas locales, pero que en general estaban lejos de los estándares internacionales. A su vez, dada la fuerte protección contra las importaciones, las filiales de las empresas transnacionales (a las que en adelante, en aras de la brevedad, denominaremos simplemente filiales) tendían a operar con un alto nivel de integración nacional.

En el escenario de los años 1990 habría cabido esperar que esas filiales hubieran aproximado su productividad a la frontera internacional y hubieran avanzado en la integración comercial con el resto del mundo, tendiendo a especializarse en un menor número de segmentos de negocios para ganar competitividad. A la vez, deberían haber exhibido un menor grado de integración nacional que en el pasado, debido a que operan en una economía más abierta y a la tendencia de las empresas transnacionales a emplear "proveedores globales".

Pero el nuevo escenario de los años 1990 no afectó solo a las estrategias de las empresas transnacionales. También las empresas de capital nacional en cada uno de los países del Mercosur se vieron expuestas a nuevas reglas de juego, debiendo enfrentar una incrementada competencia en sus respectivos mercados, tanto por el mayor ingreso de productos de origen extranjero como por la cuantiosa afluencia de IED.

En este contexto general, la mayor presencia de empresas transnacionales por sí sola podría haber generado impactos tanto positivos como negativos sobre las empresas locales. Uno de los mecanismos básicos de transmisión de esos impactos son los llamados derrames (efectos indirectos o secundarios). Originalmente, en la literatura especializada internacional dichos mecanismos se supusieron portadores de beneficios para las empresas locales, por ejemplo, a través del nuevo conocimiento introducido por las filiales, que permite mejorar la productividad, o mediante un más fácil ingreso a mercados de exportación abiertos por las empresas transnacionales. Sin embargo, el trabajo empírico en distintos países mostró que también podían generar perjuicios (esto es, los derrames podían ser negativos). Asimismo, los estudios examinados sugieren que el signo y magnitud de los derrames podrían variar según las capacidades y respuestas de las empresas locales ante la presencia de empresas transnacionales.

En el escenario descrito, el objetivo principal de este trabajo es examinar los impactos directos e indirectos de la masiva presencia de empresas transnacionales en los países del Mercosur. De dicho examen surgirán no solo lecciones relativas a los factores que determinan el signo y la magnitud de dichos impactos, sino también valiosas sugerencias de política tendientes a mejorar el balance costo-beneficio de la IED en las economías receptoras, no solo del Mercosur, sino de los países en desarrollo en general.

El trabajo se organiza del siguiente modo. Luego de esta sección introductoria, la sección II describe las principales características y factores determinantes de la IED en los países del Mercosur. La sección III analiza los efectos de la IED sobre los países del Mercosur, considerando variables clave como la productividad, el comercio exterior, el cambio tecnológico y el crecimiento. La sección IV, por último, presenta las principales conclusiones del análisis y algunas sugerencias de política.

\section{II}

\section{Las tendencias de la inversión extranjera directa en el Mercosur}

La afluencia de inversión al Mercosur en la segunda mitad de los años 1990 fue, en valores constantes (dólares de 1982), más de diez veces superior a la de los años 1970. Los países receptores fueron casi exclusivamente Argentina y Brasil. De hecho, en los años 1990 ambos países, y particularmente Argentina, incrementaron su participación ya elevada en el acervo total de IED del Mercosur. Los gráficos 1 y 2 muestran la evolución de las corrientes de IED que ingresaron al Mercosur entre 1991 y 2004.

A su vez, el peso de la IED en las economías del Mercosur experimentó un fuerte aumento en los años 1990. 
GRÁFICO 1

Mercosur: corrientes de inversión extranjera directa hacia Argentina y Brasil, 1991- 2004

(Millones de dólares corrientes)

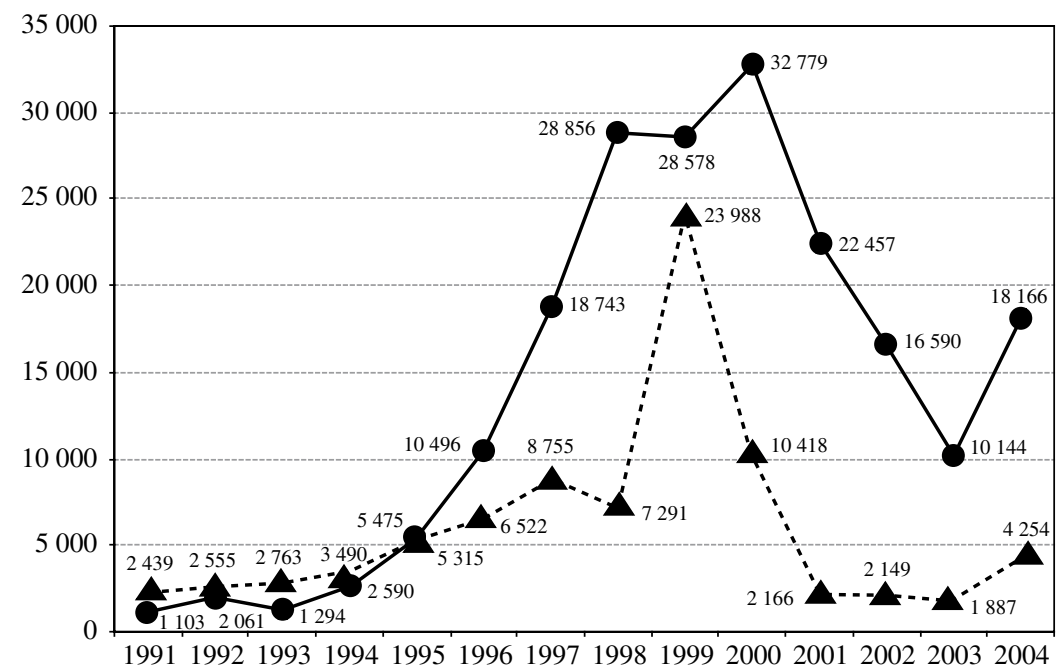

-.-.- Argentina Brasil

Fuente: elaboración propia con datos de la Conferencia de las Naciones Unidas sobre Comercio y Desarrollo (UNCTAD).

GRÁFICO 2

Mercosur: corrientes de inversión extranjera directa hacia Paraguay y Uruguay, 1991- 2004

(Millones de dólares corrientes)

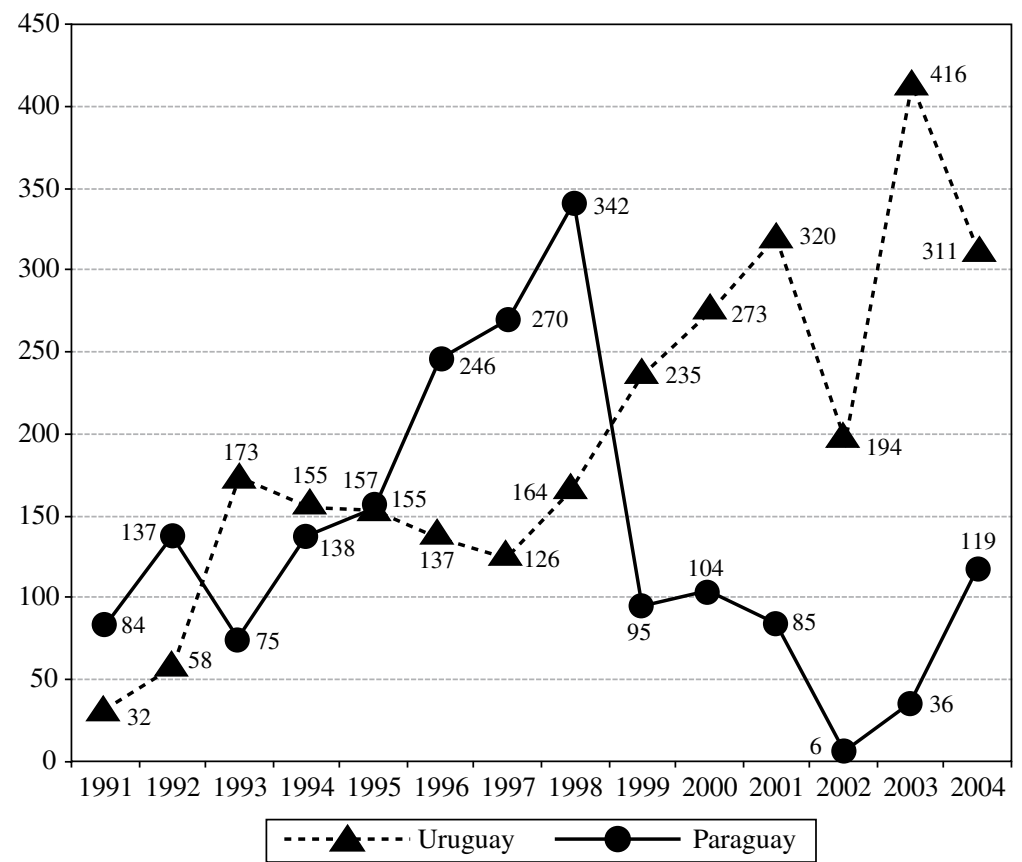

Fuente: elaboración propia con datos de la UNCTAD. 
En 2004, tanto en Argentina como en Brasil el acervo de IED como proporción del producto interno bruto (PIB) fue claramente superior al promedio mundial (cuadro 1). Naturalmente, la gran afluencia de IED al bloque causó una fuerte expansión de las empresas transnacionales en los años 1990 (gráfico 3), alcanzando en Argentina y Brasil niveles que se encuentran entre los más elevados del mundo (Chudnovsky y López, 2001).

En los años 1990 el grueso de la IED recibida por el Mercosur fue al sector servicios, fenómeno en gran medida vinculado a la oleada de privatizaciones y desregulaciones que se dio en la región. La industria recibió poco más del $20 \%$ en Argentina y Brasil, cifra muy por debajo de la observada en la etapa de la industrialización sustitutiva de importaciones. En los países más pequeños, en tanto, destacó la IED en el agro y en actividades que tienen encadenamientos con él; pero también la búsqueda de recursos naturales atrajo inversiones a Argentina, donde el sector del petróleo y la minería absorbió más de un tercio del total de inversiones llegadas al país.

En este sentido, es interesante contrastar el patrón de IED en el Mercosur con el prevaleciente en otras partes del continente. En el bloque bajo análisis, la explotación de materias primas y el acceso al mercado (nacional o regional) aparecen como los principales factores de- terminantes de la localización de la IED impulsada por estrategias de búsqueda de recursos y mercados. En México y América Central, en cambio, predominaron las inversiones impulsadas por la búsqueda de eficiencia y dirigidas al sector industrial (incluyendo ramas como la automotriz, la de productos textiles y prendas de vestir, y la electrónica), con una fuerte orientación exportadora motivada por los bajos costos laborales y con escasos encadenamientos con las economías receptoras (CEPAL, 2000).

CUADRO 1

Países del Mercosur y otros países: acervo de inversión extranjera directa, 1980-2004 (Porcentaje del PIB)

\begin{tabular}{lcccc}
\hline & 1980 & 1990 & 2000 & 2004 \\
\hline Argentina & 2,6 & 6,2 & 23,8 & 35,3 \\
Brasil & 7,1 & 8,0 & 17,1 & 25,2 \\
Paraguay & 4,8 & 7,6 & 17,2 & 14,6 \\
Uruguay & 4,4 & 7,2 & 10,4 & 17,5 \\
Países en desarrollo & 4,9 & 9,8 & 26,2 & 26,4 \\
Países desarrollados & 5,0 & 8,2 & 16,3 & 20,5 \\
Mundo & 4,9 & 8,4 & 18,3 & 21,7 \\
\hline
\end{tabular}

Fuente: elaboración propia con datos de la UNCTAD.

GRÁFICO 3

\section{Mercosur: participación de las empresas transnacionales en las ventas de las empresas líderes en los países miembros, 1992, 2000 y 2003 (Porcentajes $)^{\mathrm{a} b}$}

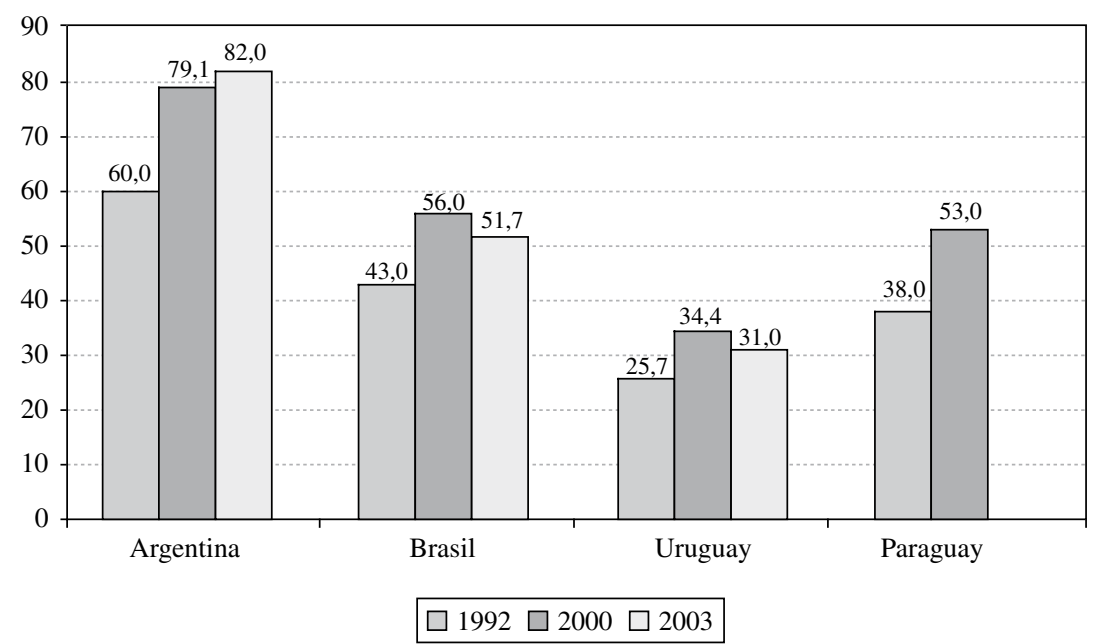

Fuente: elaboración propia con datos de la Encuesta Nacional a Grandes Empresas, del Instituto Nacional de Estadística y Censos (INDEC), de Argentina; Revista Exame (Brasil), y MC Consultores (Uruguay).

a En el caso argentino no hay datos para 1992, por lo cual se tomó el año 1993. Esta aclaración vale también para los gráficos 4 y 5.

b Los datos de la participación de las empresas transnacionales se calculan sobre un universo de 500 empresas en Argentina y Brasil y de 300 en Uruguay. Esta aclaración vale también para los gráficos 4 y 5. 
En gran medida, el auge de la IED en el Mercosur durante los años 1990 es un correlato del mismo fenómeno a nivel mundial. Sin embargo, también obedece a factores internos propios, considerando además que esta zona incrementó más que otras su participación en la recepción de IED. Sobre la base de los hallazgos recogidos en Chudnovsky y López (2002), podemos decir que el tamaño y la expansión del mercado interno de los países del bloque, la dinámica exportadora, la estabilidad macroeconómica y los recursos naturales, particularmente en Argentina, Paraguay y Uruguay, han sido factores relevantes en la atracción de IED.

Algunos instrumentos de política, las privatizaciones, la desregulación y la apertura comercial, así como los mecanismos de capitalización de deuda (utilizados activamente hacia fines de los años 1980), tuvieron un efecto positivo sobre el ingreso de IED al Mercosur. Por otro lado, el impacto del Mercosur en la atracción de IED no parece haber sido demasiado significativo, salvo en el sector automotriz, donde también se aplicaron políticas específicas en Argentina y Brasil (Chudnovsky y López, 2002).

En los gráficos 1 y 2 se observa la fuerte caída de las corrientes de IED hacia el Mercosur a partir del 2000, caída particularmente notoria en Argentina. Sin embargo, los flujos recibidos siguen siendo altos en una comparación histórica y la IED continúa ganando peso relativo en todos los países de la región, salvo Paraguay (cuadro 1). En otras palabras, aun tras las crisis sufridas por los países del bloque, la presencia de empresas transnacionales sigue teniendo una importancia decisiva para el desenvolvimiento económico del Mercosur. Esto confiere una importancia todavía mayor al estudio de los efectos de la IED, a lo cual se aboca la sección siguiente.

\section{III}

\section{Los efectos de la inversión extranjera directa en los países del Mercosur}

\section{Consideraciones generales}

La contribución de la IED al desarrollo económico de los países receptores depende fundamentalmente del efecto que tenga la presencia de empresas transnacionales - que canalizan la mayor parte de las corrientes de inversión extranjera - sobre las economías en las cuales se instalan.

Las filiales de las empresas transnacionales (a las que en aras de la brevedad llamaremos en adelante simplemente "filiales") disfrutan de "ventajas de propiedad" derivadas del acceso a las tecnologías de producto y de proceso, y a las prácticas organizacionales, productivas, comerciales y ambientales de sus casas matrices. Así, dichas filiales —en particular cuando se instalan en países en desarrollo - generalmente tienen sobre sus competidores locales las ventajas de una mayor productividad y una superior capacidad de lanzar nuevos productos y procesos productivos al mercado.

Asimismo, la IED debería influir en las corrientes de comercio de los países receptores, ya que las filiales se integran en redes corporativas que, teóricamente, facilitarían el intercambio de bienes y servicios con otras filiales, con la casa matriz e incluso con terceros (proveedores y otros). Por sus superiores niveles de productividad y mayor facilidad de acceso a los mercados extranjeros, cabe suponer que dichas filiales tendrán una mayor propensión a exportar que las empresas locales. Asimismo, se puede pensar que por su mayor posibilidad de abastecerse desde el exterior, tanto de insumos y bienes finales como de bienes de capital, tenderán a operar con una mayor propensión a importar que las empresas locales.

Además de los efectos directos de la IED, también pesan sus efectos indirectos (llamados también efectos secundarios o derrames), esto es, aquellos que recaen sobre las empresas de capital nacional. En cuanto a la productividad, por ejemplo, podría haber derrames positivos para las empresas de los países receptores, que se manifestarían por distintas vías:

i) El mejoramiento del capital humano gracias a que las empresas e instituciones locales podrían disponer de operarios, técnicos e ingenieros capacitados en actividades de producción, comercialización y/o innovación por las filiales de empresas transnacionales.

ii) El ingreso de nuevas empresas transnacionales o el aumento de la competitividad de las filiales ya instaladas puede elevar el nivel de competencia en el 
mercado interno e inducir a las empresas locales que compiten con las extranjeras a elevar su productividad y/o a mejorar la calidad de sus productos, ya sea realizando inversiones o beneficiándose de filtraciones de conocimiento desde las filiales, es decir, mediante derrames horizontales o intrasectoriales.

iii) Los beneficios que las empresas locales pueden obtener de las tecnologías y prácticas organizativas de las empresas transnacionales a través de las mayores exigencias de calidad, precio y/o plazo de entrega que las filiales suelen exigir a sus proveedores y de la asistencia técnica que puedan brindar para satisfacer esas exigencias, es decir, mediante efectos de derrame verticales o intersectoriales.

Mientras que las filiales tendrían incentivos para evitar los derrames horizontales, podrían verse estimuladas a promover los derrames verticales o intersectoriales. Este tipo de derrames probablemente no perjudicaría a dichas empresas y quizá podría beneficiarlas si vuelve más productivos y eficientes a sus clientes y/o proveedores (Kugler, 2001).

Las filiales pueden generar también efectos de derrame positivos para la entrada a los mercados externos, si su actividad de exportación reduce el costo del acceso a información sobre dichos mercados externos o facilita el aprendizaje de las empresas locales en materia de exportaciones, ya sea por efecto demostración o por generar una mayor competencia.

Sin embargo, los efectos secundarios, o derrames, no siempre serán positivos. Por ejemplo, los efectos sobre la productividad pueden ser negativos cuando las empresas locales se ven forzadas a reducir su producción - lo que conlleva menor productividad en sus establecimientos - ante la creciente presencia en el mercado de empresas extranjeras (Aitken y Harrison, 1999). Los derrames verticales negativos, en tanto, pueden aparecer cuando, por ejemplo, los proveedores locales son desplazados del mercado por sesgos de las filiales en favor de proveedores extranjeros.

Desde hace varios años se han llevado adelante estudios empíricos para tratar de captar la existencia, magnitud y signo de los efectos directos e indirectos de la IED sobre los países receptores. La metodología empleada para realizar dichos estudios ha ido variando con el tiempo. Así, los estudios de caso de países o industrias donde las empresas transnacionales tienen una participación gravitante, han sido crecientemente reemplazados por estudios econométricos, ya que es fundamental utilizar procedimientos que permitan tomar en cuenta características observables y no observables de las empresas y, de esa forma, aislar la importancia de la variable propiedad extranjera en las diferencias de desempeño; esto implica analizar el problema de endogeneidad (Barba Navaretti y Venables, 2004).

Lo mismo vale para los derrames. En el caso de los derrames de productividad, que fueron los primeros en captar la atención de la literatura especializada, la mayoría de los estudios pioneros encontraba evidencia de efectos indirectos positivos, pero estaban basados en datos de corte transversal, lo que impedía captar la heterogeneidad a nivel de la empresa. Por lo demás, estos estudios no tomaban en cuenta el efecto de la composición sectorial de la IED, de modo que aun en ausencia de derrames podría aparecer una correlación positiva entre la presencia de empresas transnacionales y la productividad de las empresas locales, simplemente porque las primeras tienden a invertir en sectores de alta productividad.

Los estudios más recientes, basados en su mayoría en técnicas de datos de panel, tienden a mostrar una realidad más heterogénea. Los modelos de datos de panel que emplean efectos fijos a nivel de la empresa permiten que se tome en cuenta aspectos no observables que pueden afectar las decisiones de inversión de las empresas transnacionales, y además permiten considerar los cambios que pueden afectar la productividad de dichas empresas en el tiempo, debidos por ejemplo a modificaciones en el contexto institucional o macroeconómico, o a una posible demora de las empresas locales en absorber los derrames de conocimiento de las filiales.

Hasta ahora nuestro análisis ha considerado básicamente los efectos microeconómicos de la IED. De manera correspondiente, los trabajos empíricos respectivos usualmente se basan en datos a nivel de la empresa. Sin embargo, los estudios examinados también han pasado revista la relación entre IED y crecimiento, tema que naturalmente debe ser tratado a nivel de país.

En tal caso, el análisis por lo general no solo explora el influjo de la IED sobre el crecimiento del producto interno bruto (PIB) de los países receptores, sino que también analiza la causalidad inversa, esto es, si el crecimiento es lo que motiva a la IED (hipótesis plausible a la luz del predominio antes mencionado de la IED horizontal, o busca de mercado, en las décadas recientes). Como veremos más adelante, también en esta área la evidencia empírica ha ido cambiando de signo — del optimismo al escepticismo, en general — al irse utilizando técnicas econométricas cada vez más avanzadas.

\section{Productividad}

Si bien muchos trabajos empíricos han señalado que las filiales exhiben mayores niveles de productividad que 
las empresas locales, cuando se controla por otras características observables y no observables de las empresas el rango de las diferencias se reduce apreciablemente: de entre 30 y $70 \%$ cae a entre 1 y $7 \%$ (Barba Navaretti y Venables, 2004). Asimismo, cuando se toma en cuenta el hecho de que las empresas transnacionales pueden adquirir las empresas locales que ya tienen la mayor productividad, en algunos casos el efecto nacionalidad se desvanece, aunque en ninguno se observan efectos negativos.

En lo que hace a derrames horizontales, los estudios más recientes, basados en procedimientos econométricos avanzados, no encuentran mucha evidencia de efectos positivos, especialmente en los países en desarrollo. Parte de esos estudios tiende a subrayar que la magnitud y el signo de estos derrames pueden depender sobre todo de las capacidades de las empresas locales y/o de la distancia tecnológica entre ellas y las filiales. ${ }^{1}$

En contraste, respecto a los derrames verticales -que han sido mucho menos estudiados que los horizontales- los trabajos de Javorcik (2004) y de Blalock y Gertler (2005) sugieren que hay derrames positivos desde las filiales de las empresas transnacionales a sus proveedores locales, confirmando la intuición antes mencionada de que dichos derrames podrían ser, al contrario de los horizontales, beneficiosos para esas empresas.

En el caso del Mercosur, los estudios realizados sobre los efectos indirectos de las empresas transnacionales en Argentina, Brasil y Uruguay, cuyos hallazgos han sido publicados en Laplane (2006), siguen la metodología econométrica predominante en cuanto a análisis de derrames, pero la complementan con una consideración del contexto local con el propósito de hallar explicaciones para los resultados obtenidos.

En Argentina, en un panel de datos de empresas manufactureras para el período 1992-2001 se verifica que las filiales exhiben mayores niveles de productividad que las empresas locales. No hay evidencia de derrames positivos o negativos sobre las empresas locales que deriven de la presencia de empresas transnacionales, lo que es válido respecto de derrames tanto horizontales como verticales. Sin embargo, las empresas locales que poseen altas capacidades de absorción - medidas por un indicador que combina variables vinculadas a capital humano, actividades de innovación y uso de técnicas modernas de gestión- se encuentran en

\footnotetext{
${ }^{1}$ Véase reseñas y balances críticos de la literatura sobre el tema en Görg y Greenaway (2004) y Lipsey y Sjoholm (2005).
}

mejores condiciones para recibir derrames positivos de la presencia de empresas transnacionales que aquellas con bajas capacidades de absorción (Chudnovsky, López y Rossi, 2006).

En el caso de Brasil, un panel de datos de firmas industriales para el período 1997-2000 muestra que las empresas nacionales en su conjunto no recibieron derrames positivos ni negativos debidos a la presencia de empresas transnacionales. Al igual que en Argentina, se observó que la capacidad de respuesta de las empresas nacionales condiciona los resultados de su interacción con las filiales. Así, las empresas nacionales que tenían una menor diferencia de productividad con las extranjeras mostraron derrames negativos derivados de la presencia de empresas transnacionales. En contraste, dicha presencia benefició, en términos de productividad, a las empresas nacionales que exhibían una brecha mayor (Laplane, Padovani Gonçalves y Dias de Araújo, 2006).

Los autores interpretan este resultado a la luz del hecho de que, durante el período analizado, la mayor parte de las filiales estaba orientada predominantemente al mercado interno brasileño. Así, su presencia habría tenido principalmente el efecto de reducir la escala de actividad de las empresas locales más eficientes, con la consecuente pérdida de productividad. Esta hipótesis se refuerza al constatarse que la presencia de filiales con estrategias de busca de mercados tiene un efecto negativo sobre la productividad de las empresas nacionales. En cuanto a efectos verticales, el estudio brasileño halló evidencia de derrames positivos para las empresas de capital local.

En Uruguay, al igual que en Brasil, se hallaron efectos horizontales negativos (aunque no en todos los ejercicios realizados en el trabajo respectivo), atribuidos a la disputa por el mercado interno entre empresas locales y filiales. En tanto, se encontró que las empresas nacionales con mayor capacidad de aprendizaje — medida por el personal dedicado a actividades de investigación y desarrollo (I+D) — lograron beneficiarse de la presencia extranjera; en cambio, las empresas con mayor nivel de gasto en I+D vieron descender su productividad como resultado de dicha presencia (Bittencourt y Domingo, 2006). Finalmente, se verificó que las empresas transnacionales son más productivas que las locales cuando se trabaja con efectos fijos por sector, pero dicho resultado no se mantiene cuando se emplean efectos fijos por empresa.

Si bien en Argentina también las estrategias de las empresas transnacionales obedecieron predominantemente a la busca de mercados, en dicho país, a diferencia de Brasil y Uruguay, no se encontró evidencia de derrames 
horizontales negativos. Sin embargo, Chudnovsky, López y Rossi (2006) encontraron que en los sectores con protección efectiva elevada la presencia de empresas transnacionales tuvo efectos negativos sobre la productividad de las empresas locales. De algún modo, esto también va en la dirección de subrayar el impacto negativo de la IED cuando se dirige principalmente a explotar los mercados de los países receptores.

\section{Comercio exterior}

Son relativamente pocos los estudios del efecto de la IED sobre el comercio exterior de los países receptores. ${ }^{2}$ Algunos trabajos encuentran que las filiales exportan más que las empresas nacionales. ${ }^{3}$ En contraste, no hemos encontrado evidencia de estudios empíricos basados en técnicas econométricas que muestren que las empresas transnacionales importan más que las locales (de hecho, este parece ser un tema poco analizado aún), salvo los que se hicieron en Argentina, Brasil y Uruguay (véase más adelante).

En lo que respecta a derrames, algunos estudios señalan efectos positivos, pero otros trabajos no encuentran evidencia en ese sentido. ${ }^{4}$

El tema es muy importante para el Mercosur, considerando el importante papel de las empresas transnacionales en el comercio exterior de los países de la región. En Argentina dicho papel es mayor y con clara tendencia ascendente, en particular en materia de exportaciones; le siguen Brasil y Uruguay (gráficos 4 y 5).

¿Cuál es la evidencia empírica respecto de la propensión a comerciar de las filiales y de los posibles derrames hacia las empresas locales en el caso del Mercosur? En un estudio sobre un panel de empresas manufactureras en Argentina, con datos del período 1992-2001, Chudnovsky, López y Orlicki (2006) encuentran que las empresas que fueron adquiridas por inversores extranjeros, luego del cambio de propiedad, aparecen exportando e importando más (tanto en valores absolutos como con respecto a la facturación) que las empresas nacionales cuando se toman en cuenta diversas características observables y

\footnotetext{
${ }^{2}$ Véase una reseña en Görg y y Greenaway (2004).

${ }^{3}$ Véase en Roper y Love (2001) un estudio con datos sobre la República de Irlanda e Irlanda del Norte; en Aitken, Hanson y Harrison (1997) uno con datos sobre México, y en Kneller y Pisu (2004) uno con datos sobre Gran Bretaña.

${ }^{4}$ Entre los primeros, véase Aitken, Hanson y Harrison (1997), con datos sobre México; Greenaway, Sousa y Wakelin (2004), sobre Gran Bretaña, y Alvarez (2005) sobre Chile. Entre los segundos véase Barrios, Görg y Strobl (2003), con datos de panel sobre empresas españolas.
}

no observables de las empresas analizadas. Este efecto se da en forma gradual y es robusto a diversas especificaciones del modelo. En dicho estudio no se encuentra evidencia acerca de derrames verticales u horizontales sobre las empresas nacionales.

En cambio, existen varios estudios sobre el desempeño comercial de las empresas transnacionales en Brasil que utilizan diferentes bases de datos y metodologías. Empleando datos de 1997, Pinheiro y Moreira (2000) verificaron que las empresas de capital extranjero tenían más probabilidades de exportar y que el valor esperado de sus exportaciones era $32 \%$ mayor que el de las empresas nacionales. De Negri (2003), en tanto, analiza un panel para casi 54.000 empresas en el período 1996-2000 y encuentra que las extranjeras exportaban un $70 \%$ e importaban un $290 \%$ más que las nacionales.

En cuanto a efectos de derrame, un trabajo reciente muestra que ellos existen pero son en general de muy pequeña magnitud y de signos heterogéneos (Hiratuka y Dias de Araújo, 2006). Por un lado, la presencia extranjera parece favorecer la probabilidad de que las empresas nacionales del mismo sector exporten; sin embargo, cuando los autores desagregan el análisis, clasificando las empresas nacionales por sus niveles de productividad relativa frente a las empresas transnacionales, los efectos se tornan negativos. En tanto, al estudiar los derrames de la presencia extranjera sobre los montos exportados por las empresas locales se observan efectos positivos en aquellas con niveles de productividad altos, y efectos negativos en las restantes.

En el caso de Uruguay, un estudio de corte transversal halla que la presencia de empresas transnacionales aumenta la probabilidad de que las locales exporten, aunque este efecto solo se da para las exportaciones al mercado mundial, y no para las realizadas a Argentina y Brasil. Interesantemente, solo las filiales establecidas después de 1973 tienen un efecto positivo sobre la posibilidad de exportar de las empresas locales, mientras que no ocurre lo mismo con las instaladas en el período de industrialización mediante la sustitución de importaciones (Kokko, Zejan y Tansini, 2001).

Más recientemente, Bittencourt, Domingo y Reig (2006a), basándose en dos paneles de empresas uruguayas para distintos períodos de los años 1990, muestran que las empresas transnacionales tienen una mayor propensión a exportar que las locales, pero no encuentran efectos indirectos de este hecho sobre el comportamiento exportador de las empresas locales. En cuanto a la propensión importadora, tomando solo las compras de insumos, encuentran que las transnacionales 
GRÁFICO 4

Mercosur: participación de las empresas transnacionales en las exportaciones de empresas líderes en los países miembros, 1992, 2000 y 2003

(Porcentajes)

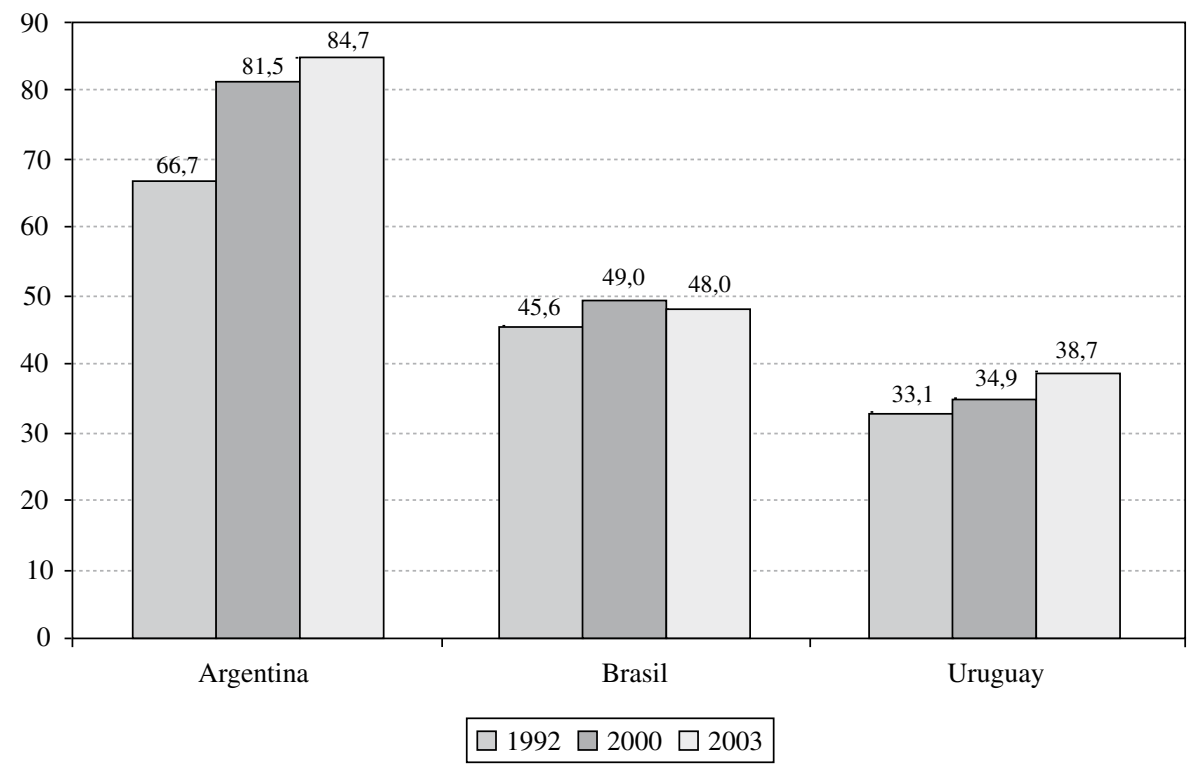

Fuente: elaboración propia con datos de la Encuesta Nacional a Grandes Empresas, del INDEC (Argentina); Revista Exame (Brasil), y MC Consultores (Uruguay).

GRÁFICO 5

Mercosur: participación de las empresas transnacionales en las importaciones de empresas líderes en los países miembros, 1992, 2000 y 2003

(Porcentajes)

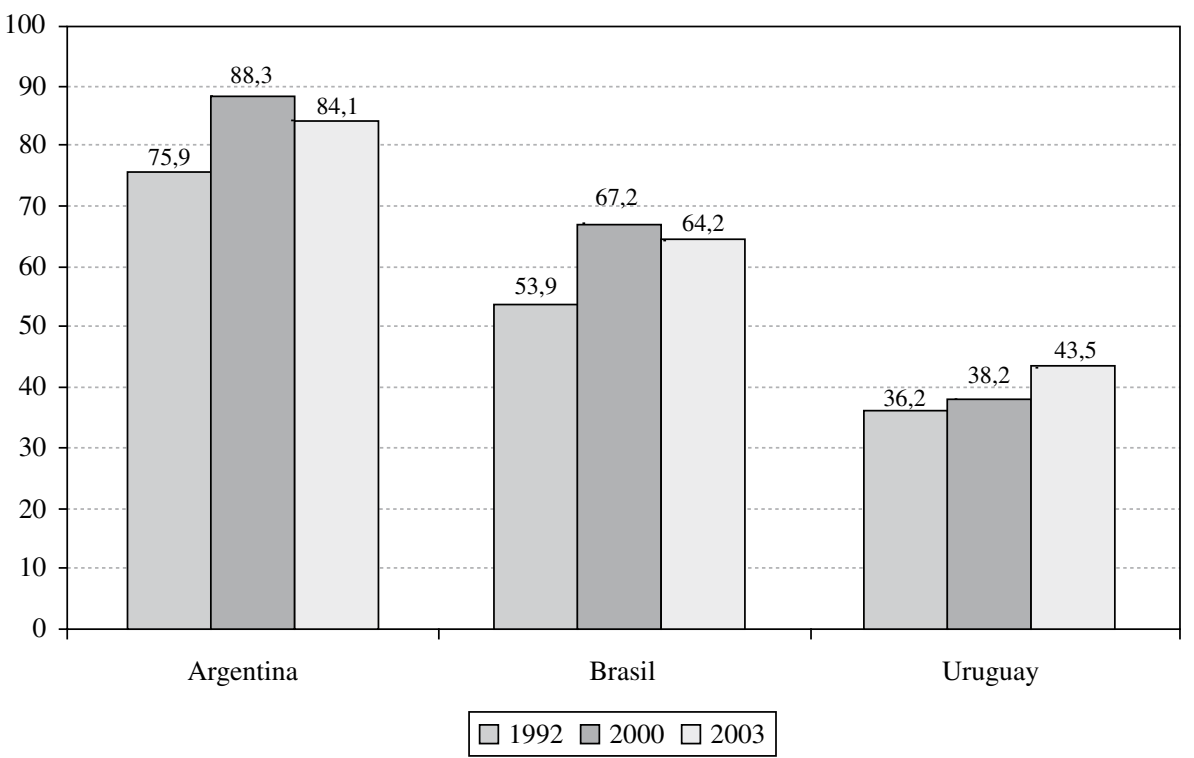

Fuente: elaboración propia con datos de la Encuesta Nacional a Grandes Empresas, del INDEC (Argentina); Revista Exame (Brasil), y MC Consultores (Uruguay). 
importan más que las locales únicamente en uno de los dos períodos con los que trabajan. Asimismo, en uno de los dos períodos analizados la presencia extranjera en una rama puede haber tenido como efecto incrementar la propensión importadora de las empresas locales.

En tanto, también se han realizado trabajos que buscan analizar no solo el desempeño comercial general de las empresas transnacionales sino también las características de su comercio exterior. En Chudnovsky y López (2001) se mostraba, a través de un análisis de estadística descriptiva, que las filiales instaladas en países del Mercosur tenían un patrón de comercio esencialmente asimétrico, ya que el contenido tecnológico de sus exportaciones era claramente inferior al de sus importaciones. En tanto, el peso de los países desarrollados -y en particular de las respectivas regiones de origen de las filiales — en la pauta importadora era superior al que tenía en las exportaciones, particularmente en el caso de bienes manufacturados.

Un trabajo reciente de Hiratuka y De Negri (2004) permitió estudiar esta misma temática para el caso brasileño mediante técnicas econométricas. Lo que muestran los autores es que las filiales con casa matriz en Estados Unidos, Canadá y Europa importan más productos desde sus regiones de origen que las demás empresas, pero no presentan diferencias significativas en cuanto a las regiones de destino de las exportaciones. A su vez, el contenido tecnológico de las importaciones realizadas por las empresas transnacionales desde su región de origen es mayor que el de sus importaciones totales. Así, el superior volumen de importaciones desde su región de origen puede deberse a la dependencia tecnológica de las filiales respecto de sus casas matrices.

Según Hiratuka y De Negri, uno de los factores principales para entender estos hallazgos es el fuerte peso del comercio intraempresa en las filiales que, según datos oficiales, llegaba al $63 \%$ de sus exportaciones y el $57 \%$ de sus importaciones. Así, en el 2000 casi $38 \%$ de las exportaciones y $33 \%$ de las importaciones totales brasileñas correspondían a comercio intraempresa.

Estos datos reflejan el posicionamiento de las filiales brasileñas en las redes de producción y comercio de las empresas transnacionales. Sin embargo, es preciso subrayar que Brasil tiene una relativa posición de privilegio en ese sentido frente a los restantes socios del Mercosur. De hecho, en este país la participación de las exportaciones manufactureras en la pauta de comercio de las empresas transnacionales es más alta, es mayor el peso de la IED en los sectores de alta tecnología y, como veremos más adelante, en él se centraliza el esfuerzo innovativo realizado a nivel regional por las filiales; asimismo, muchas de estas empresas tienen sus sedes regionales en Brasil (Chudnovsky y López, 2001). Todo esto sugiere, entonces, que los impactos de la IED en dicho país podrían ser diferentes que en los restantes socios del Mercosur.

Finalmente, en Hiratuka y Sabatini (2006) también se analiza en qué medida las empresas transnacionales tienen una mayor propensión a comerciar con el Mercosur que las nacionales. Un trabajo anterior (Chudnovsky y López, 2002), con datos de comercio para el año 2000, no había encontrado diferencias estadísticamente significativas en ese ámbito. En contraste, el estudio más reciente, basado en datos de 2003, halla que en Argentina las empresas transnacionales tienen mayor propensión a comerciar con el Mercosur, tanto desde el punto vista de las importaciones como de las exportaciones. En Brasil, en tanto, las diferencias son estadísticamente significativas solo en el caso de las importaciones. Esta mayor orientación regional del comercio de las empresas transnacionales podría estar reflejando la permanencia e incluso la profundización de las estrategias orientadas a la busca de eficiencia dentro del ámbito del Mercosur, así como posibles efectos de la crisis cambiaria en Argentina.

\section{Investigación y desarrollo e innovación}

Si bien las empresas transnacionales tradicionalmente han centralizado sus actividades de $\mathrm{I}+\mathrm{D}$ en sus casas matrices, y en algunos casos en sus filiales en países industrializados, en los últimos años se observa una descentralización de esas actividades con su desplazamiento hacia algunos países en desarrollo en Asia y, en menor medida, en América Latina, especialmente Brasil (UNCTAD, 2005).

El tema es relevante porque el aumento de la productividad y la competitividad en los países en desarrollo depende no solo de la incorporación de modernas tecnologías de origen importado, sino también de la realización de esfuerzos sistemáticos a nivel local en materia de $\mathrm{I}+\mathrm{D}$.

Cabe preguntarse, en este contexto, cuál ha sido el aporte de la IED a la realización de actividades de I+D en los países del Mercosur, y, siguiendo lo hecho en los apartados anteriores, indagar acerca de la existencia de derrames sobre las empresas locales.

Refiriéndonos al universo de los países en desarrollo, no son muchos los trabajos que buscan determinar si las empresas transnacionales llevan a cabo en los países receptores más o menos actividades de $\mathrm{I}+\mathrm{D}$ que las empresas locales, y son aún menos los que indagan 
posibles efectos indirectos de esas actividades en las empresas nacionales. No estamos hablando aquí de derrames de productividad, sino de averiguar si el desarrollo de actividades de I+D por las filiales incrementa o no la probabilidad de que las empresas nacionales hagan lo mismo.

Un trabajo con datos sobre Turquía (Erdilek, 2005) muestra que esas filiales tienen mayor propensión a emprender actividades de I+D que las empresas locales. A la vez, el mismo trabajo brinda evidencia, al menos en algunos de los varios ejercicios allí presentados, de que la presencia extranjera estimula la realización de tales actividades por las empresas locales que operan en el mismo sector.

En contraste, en un estudio con datos sobre la India, Kumar y Aggarwal (2000) encuentran que las filiales gastan menos en I+D que sus pares locales. En el mismo sentido, Srholec (2005), trabajando con datos para la República Checa, encuentra que las empresas transnacionales son menos propensas que las locales a realizar actividades de I+D. Un hallazgo similar aparece en Jefferson, Huamao y otros (2002) para un panel de datos de empresas chinas.

¿Cuál es la evidencia disponible para el Mercosur? Utilizando los datos cuantitativos de la encuesta brasileña de innovación para el año 2000, Laplane, Padovani Gonçalves y Dias de Araujo (2006) efectuaron varios ejercicios econométricos de corte transversal sobre el tema. Allí constataron que las filiales gastan proporcionalmente menos en I+D que las empresas nacionales, si se consideran factores como tamaño, calificación del personal y orientación exportadora, entre otros. Dias de Araújo (2005) presenta un resultado similar, ya que encuentra que las empresas transnacionales son menos propensas a gastar en I+D que sus pares locales. Esto, como lo aclaran los autores, no significa que las filiales innoven menos que sus contrapartes nacionales (la encuesta mencionada revela que el $68 \%$ de las filiales extranjeras son innovadoras, ${ }^{5}$ contra el $30 \%$ de las empresas nacionales), sino que utilizan con ese objetivo conocimientos provistos fundamentalmente por sus respectivas casas matrices.

Al mismo tiempo, Laplane, Padovani Gonçalves y Dias de Araújo (2006) encontraron que tanto la presencia extranjera como la intensidad media de los gastos en I+D de las empresas transnacionales que actúan en un determinado sector estimulan el esfuerzo en I+D dentro

\footnotetext{
${ }^{5}$ Definimos como empresa innovadora a aquella que, durante los períodos analizados por los respectivos estudios, fue capaz de lanzar nuevos productos $\mathrm{y} / \mathrm{o}$ procesos al mercado.
}

de las locales. Sin embargo, los efectos de derrame son relativamente pequeños. También Dias de Araújo (2005) encuentra efectos de derrame predominantemente positivos (aunque, dado que el autor diferencia las empresas locales y extranjeras por tipo de sector y niveles de productividad, también halla algunos casos minoritarios de efectos indirectos negativos).

En el caso argentino, en un estudio sobre insumos y resultados del proceso de innovación en la industria manufacturera en 1992-2001 que se realizó con datos emanados de dos encuestas sobre innovación llevadas a cabo en los últimos años, el origen del capital de la empresa no resultó ser una variable explicativa ni del nivel de gastos en I+D como proporción de las ventas, ni de la posibilidad de lanzar innovaciones al mercado (Chudnovsky, López y Pupato, 2006).

Otro estudio, en tanto, muestra que las empresas adquiridas por inversores extranjeros tenían una mayor probabilidad que las empresas locales de introducir nuevos productos o procesos al mercado, pero que la adquisición de empresas locales por empresas transnacionales no influía en el nivel de gastos en I+D ni tampoco se registraban derrames horizontales o verticales hacia las empresas nacionales (Chudnovsky, López y Orlicki, 2006). Estos hallazgos van en el mismo sentido de lo encontrado en Brasil - las filiales de una empresa transnacional pueden ser más innovadoras debido al conocimiento que reciben desde la propia empresa.

Dentro del Mercosur, las filiales en Brasil son claramente las que tienen mayor protagonismo en el área de $\mathrm{I}+\mathrm{D}$, tanto a nivel regional como internacional. ${ }^{6}$ Por un lado, esto podría deberse a que el despliegue de estrategias orientadas a la busca de eficiencia en este bloque pudo haber llevado a abandonar ciertas actividades innovadoras de carácter adaptativo que se realizaban en las filiales argentinas y trasladarlas a sus pares brasileñas. Por otro, cabe recordar que Brasil ha atraído más IED hacia sectores de alta tecnología, en los cuales el gasto en $\mathrm{I}+\mathrm{D}$ tiende a superar el promedio, que los otros miembros del Mercosur. A la vez, por regulaciones vigentes en Brasil, las empresas transnacionales que invierten en sectores como electrónica y computación deben invertir un determinado quantum de sus ventas en actividades de I+D.

\footnotetext{
${ }^{6}$ Una encuesta reciente de la UNCTAD a un conjunto de grandes empresas transnacionales muestra que Brasil ocupa el puesto 12 entre las localizaciones extranjeras para llevar a cabo actividades de $\mathrm{I}+\mathrm{D}$, mientras que Argentina recibió solo una mención, y Uruguay y Paraguay no fueron mencionados.
} 


\section{Crecimiento}

En los últimos años ha habido un extenso debate acerca de las relaciones entre IED y crecimiento. Algunos trabajos han mostrado que la IED es un factor causal del crecimiento en los países en desarrollo, particularmente cuando en los países receptores se alcanzan ciertos umbrales mínimos de capital humano y/o apertura (Borenztein, de Gregorio y Lee, 1998; Blonigen y Wang, 2005; Zhan, 2001).

En contraste, Carkovic y Levine (2005), empleando nuevas técnicas econométricas, no hallan evidencia de efectos positivos de la IED en el crecimiento. En la misma dirección van los trabajos de Calderón, Loayza y Serven (2004), ${ }^{7}$ quienes encuentran que la relación causal va desde el crecimiento a la IED, y de Mencinger (2003), quien estudia las economías en transición del Este europeo y llega a la conclusión de que allí la IED tuvo un efecto negativo sobre el crecimiento - el autor lo atribuye al predominio de las fusiones y adquisiciones como objetivo de la IED arribada a la región.

En tanto, otros trabajos muestran evidencia más heterogénea. Por ejemplo, Chowdhury y Mavrotas (2005) encuentran que la IED y el crecimiento se determinan mutuamente en los casos de Tailandia y Malasia, pero que en Chile la relación causal va del crecimiento a la IED. En tanto, Cuadros, Orts y Alguacil (2004), trabajando con datos de varios países latinoamericanos, comprueban un efecto positivo de la IED sobre el crecimiento solo en el caso de México. Basu, Chakraborty y Reagle (2003) concluyen que en economías abiertas la IED y el crecimiento se retroalimentan, pero que en economías cerradas la relación es unidireccional: del crecimiento a la IED. Choe (2003), en tanto, también halla evidencia de una relación bidireccional entre IED y crecimiento, pero señala que los efectos más fuertes van del segundo a la primera.

¿Qué dice la información disponible al respecto en el caso del Mercosur? Un trabajo de Bittencourt, Domingo y Reig (2006b) explora esta cuestión mediante dos metodologías: un análisis de las relaciones de integración y causalidad entre las series de IED, inversión y PIB para los países del bloque, y el uso de un modelo de crecimiento con paneles de países (que son las metodologías aplicadas en los estudios arriba mencionados). En ninguno de los dos casos se encuentra evidencia de que la IED genere crecimiento.

Explorando la dinámica de las relaciones entre las series mencionadas para el período 1950-2004, los autores recién mencionados encuentran que respecto a ninguno de los países del Mercosur puede afirmarse que la IED haya contribuido al crecimiento del producto interno bruto (PIB), aunque la relación inversa se comprueba para Uruguay y, débilmente, para Argentina. Solo en Uruguay habría una relación positiva, de carácter bidireccional, entre la IED y la inversión interna.

En tanto, con un panel para el período 1970-2004 integrado por los cuatro países miembros del bloque, Bittencourt, Domingo y Reig (2006b) encuentran efectos positivos sobre el crecimiento de variables representativas de la acumulación de capital físico y humano, así como de la tasa de crecimiento del período previo, pero la IED no resulta una variable explicativa de significación. En resumen, la IED no parece haber tenido efectos positivos (aunque tampoco negativos) sobre el crecimiento de los países del Mercosur en las últimas décadas.

\section{IV}

\section{Conclusiones y recomendaciones de política}

El análisis precedente sugiere que los impactos macroeconómicos de la IED en el Mercosur no han sido significativos, ya que su efecto sobre el crecimiento de los países de la región no fue positivo ni negativo.

\footnotetext{
${ }^{7}$ El trabajo de Carkovic y Levine (2005) y el de Calderón, Loayza y Serven (2004) cubren tanto países desarrollados como en desarrollo.
}

Esto no sorprende a la luz del hecho de que muchos de los estudios más recientes realizados sobre el tema para otras regiones apuntan en la misma dirección. En contraste, los impactos microeconómicos de la IED parecen haber sido mucho más fuertes, aunque con signos heterogéneos.

En los tres países analizados en este trabajo se halla evidencia de que las filiales están más integradas comercialmente que las empresas nacionales, tanto 
por el lado de las importaciones como por el de las exportaciones. Dado que en anteriores trabajos no se hallaba evidencia de una mayor propensión a exportar por parte de dichas filiales, el cambio podría deberse a que en ellas hubo un proceso de aprendizaje y mejoras de eficiencia resultantes de los esfuerzos por adaptarse a las nuevas condiciones del entorno local e internacional, lo cual les permitió incrementar gradualmente su capacidad exportadora.

A la vez, se observan características asimétricas en la inserción internacional de las filiales en las corrientes de comercio dentro de las empresas transnacionales. En particular, se ha mostrado que en Brasil las filiales de empresas transnacionales provenientes de países desarrollados tienden a importar preferentemente desde sus países de origen - mientras que no muestran similar propensión en el área de las exportaciones-, a la vez que el contenido tecnológico de tales importaciones es superior al de las importaciones que realizan desde otras regiones.

Considerando que el grueso del comercio de las filiales de empresas transnacionales es de tipo intrafirma, y teniendo en cuenta hallazgos descritos en estudios previos sobre el tema, ${ }^{8}$ podemos concluir que, al menos en una parte importante de las empresas extranjeras con operaciones en la región, predomina una suerte de "división del trabajo" intraempresa.

El contenido tecnológico de las exportaciones de las filiales es inferior al de sus importaciones, y el grueso de tales exportaciones va a países en desarrollo - sobre todo de América Latina-, sin que se aprovechen las posibilidades que podrían abrirse para las filiales en los mercados de origen de sus respectivas casas matrices. En contraste, las filiales tienden a abastecerse predominantemente desde sus países de origen, en particular cuando se trata de bienes con mayor contenido tecnológico.

En cuanto a los efectos de derrame de la IED sobre las empresas nacionales, la información disponible sugiere un panorama heterogéneo. Solo en el caso de Brasil parecen existir derrames de productividad desde las filiales de empresas transnacionales hacia las firmas nacionales que son sus proveedoras. Así, estas últimas parecen haber mejorado su productividad debido a la presencia extranjera, lo cual puede deberse incluso a esfuerzos conscientes de las filiales por contribuir a elevar los niveles de eficiencia de sus proveedores.

En contraste, los derrames horizontales de productividad —esto es, entre empresas competidoras

${ }^{8}$ Véase Chudnovsky y López (2001 y 2002). en una misma rama-, parecen depender de una serie de características de las empresas locales y de los mercados en donde se desenvuelven. En general, no hubo evidencias de derrames horizontales positivos ni negativos, aunque al desagregar el segmento de empresas nacionales según distintas clasificaciones, surgen efectos diferenciados. Así, en Argentina las empresas locales con mayor capacidad de absorción se beneficiaron de la presencia de las transnacionales, en tanto que en Brasil ocurrió lo propio con las empresas nacionales que tenían mayor diferencia de productividad con las transnacionales. Mientras que en el primer caso la hipótesis detrás del mencionado hallazgo remite al hecho de que las mayores capacidades de absorción facilitan la transferencia de conocimiento desde las filiales de empresas transnacionales hacia las firmas locales, en el segundo la explicación pasaría por el efecto que tendría la llegada masiva de IED a un país con miras a aprovechar su mercado interno, desplazando a las empresas locales que compiten directamente con las filiales extranjeras en los mismos mercados.

Por otra parte, no hay evidencia de derrames sobre la actividad exportadora de las firmas nacionales que deriven de la presencia de filiales de empresas transnacionales, salvo en Brasil, donde dichos derrames parecen haber existido, pero en magnitudes muy pequeñas y con signos heterogéneos, beneficiando en general a las empresas locales de mayor productividad y perjudicando a las de menor productividad.

A la vez, también en Brasil, hay evidencia de derrames positivos de la presencia extranjera sobre los gastos en I+D de las empresas locales. Curiosamente, esto se da aun cuando en dicho país las filiales gastan menos en tal rubro que las empresas nacionales. Esto, sin embargo, no les impide ser más innovadoras —en otras palabras, en Brasil, así como en Argentina, las empresas transnacionales tienen más probabilidades de lanzar innovaciones al mercado que las locales-, lo cual se explica porque el conocimiento existente dentro de la empresa transnacional puede ser aprovechado a bajo costo por sus filiales.

¿Cómo interpretar este conjunto de hallazgos? Claramente, no sugieren que la IED sea una panacea para el crecimiento ni para mejorar generalizadamente el desempeño empresarial en los países receptores, como tendían a suponer de manera explícita o implícita los sostenedores del llamado Consenso de Washington, que inspiró la oleada de reformas de los años 1990. Sin embargo, tampoco avalan la actual percepción mayoritariamente negativa de la IED que ha cundido en los últimos años en varios países de la región. 
Más aún, de la evidencia disponible se desprende que los efectos de la IED en los países del Mercosur no han sido necesariamente homogéneos. Brasil parece ser el país más beneficiado en ese sentido, ya que allí: i) tienden a centralizarse funciones clave para la empresa transnacional a nivel regional $y$, en un puñado de casos, a nivel global; ii) se radica el grueso de la IED de alta tecnología que llega al Mercosur; iii) el contenido tecnológico de las exportaciones de las empresas transnacionales es mayor. Estas tendencias derivan de una combinación de factores estructurales (el mayor tamaño de la economía brasileña, su superior desarrollo industrial) y de política pública (existencia de regímenes que incentivan a las empresas transnacionales a emprender actividades de $\mathrm{I}+\mathrm{D}$ en Brasil y atraen inversiones a sectores de alta tecnología).

En este escenario, ¿cuál es la agenda de aquí en adelante en materia de formulación de políticas públicas? Ante todo cabe considerar que aun tras las crisis cambiarias de Argentina -más fuertes conflictos con inversores extranjeros vinculados a las privatizaciones-y de Brasil, así como la caída de la IED a nivel global después del 2001, las corrientes de inversión que afluyen a la región siguen siendo altos en la comparación histórica. Asimismo, pese a que el proceso de "desnacionalización" de las respectivas cúpulas empresarias parece haberse desacelerado en los últimos años, las filiales de empresas transnacionales siguen teniendo mucho peso en las economías de la región. De aquí que la agenda de las políticas públicas se vincule no solo con lo que debe hacerse respecto al acervo de IED existente en la región, sino también con las estrategias frente a los inversores extranjeros que siguen atraídos por las oportunidades que ofrece el Mercosur.

A la vez, cabe señalar que, a diferencia de lo que ocurría en los años 1990 — cuando las políticas para promover la competitividad y la innovación habían sido relegadas a un plano secundario, o se suponía que se identificaban con las reformas estructurales de aquella década-, en años recientes se observa un saludable retorno de la discusión acerca de si dicho tipo de instrumentos tiene un lugar en la agenda de los países en desarrollo.

Lo expuesto sugiere varios campos para aplicar medidas de política que podrían mejorar los efectos directos e indirectos de la IED en los países del Mercosur, entre otras las siguientes:

i) fortalecimiento de las capacidades y competencias de las empresas locales, en particular las pymes, con miras a que ellas aprovechen mejor los efectos de derrame de la presencia extranjera; esto abarca entre otros aspectos el reforzamiento de los mecanismos de transferencia de tecnología, la intensificación de las acciones de capacitación y la difusión de esquemas modernos de organización productiva y comercial;

ii) profundización de las políticas de incentivo a las actividades de $\mathrm{I}+\mathrm{D}$, tanto para las empresas transnacionales como para las empresas de capital nacional;

iii) establecimiento de negociaciones tendientes a que las empresas transnacionales radiquen en sus filiales en el Mercosur actividades de mayor contenido estratégico para ellas mismas y les adjudiquen responsabilidades, por ejemplo, en materia de desarrollo de "productos globales" que puedan ser exportados a todo el mundo;

iv) estímulo a los esquemas de creación o perfeccionamiento de proveedores, que pueden dar pie a derrames verticales importantes sobre las empresas locales, y

v) promoción de diversas formas de integración de las empresas locales en las cadenas de valor lideradas por las empresas transnacionales, incluyendo subcontrataciones externas, alianzas y otras modalidades que se han ido difundiendo a nivel mundial pero que han tenido escaso desarrollo en los países del Mercosur.

Del listado anterior se desprende con bastante claridad que una parte sustantiva de las medidas de política necesarias para que la afluencia de IED al Mercosur tenga mayores efectos de derrame guarda relación con el desarrollo empresarial de los países del bloque. Ciertamente, se trata de un asunto crucial que abarca desde problemas de acceso al financiamiento -que afectan fundamentalmente a las inversiones en capital físico y cambio tecnológico de las empresas locales - hasta carencias en materia de capital humano, limitaciones de las capacidades de absorción y generación de conocimientos y retraso en la difusión de métodos modernos de gestión empresarial.

Es probable, a la vez, que las políticas "activas" frente a la IED tengan mejores resultados si las empresas transnacionales que operan en el Mercosur buscan la eficiencia (pero sin convertirse en enclaves basados en mano de obra barata), más que la mera explotación de los recursos naturales o los mercados internos, como hicieron predominantemente en los años 1990. Es necesario, por lo tanto, pensar en crear condiciones para que la IED de más "calidad" — aquella que busca eficiencia y activos estratégicos- tenga un mayor peso en la pauta de inversiones en el Mercosur. Entre esas condiciones se hallan el acceso a recursos 
humanos calificados, la disponibilidad de una adecuada infraestructura física y logística, la existencia de una base científico-tecnológica de calidad y, tema crucial, la vigencia de normas estables e instituciones sólidas (CEPAL, 2006).

El espacio para el desarrollo de políticas en estas áreas no puede ser exclusivamente nacional. Como mínimo, es imprescindible que los países involucrados coordinen sus acciones para evitar competencias de suma cero que pueden ocurrir cuando la disponibilidad de determinados instrumentos o incentivos en un país hace que simplemente se reubiquen actividades o inversiones destinadas al Mercosur, con lo cual algunos "ganan" a expensas de otros.
Para concluir, queremos destacar que, según la evidencia empírica, la IED no es en sí un fenómeno positivo ni negativo, sino que su impacto depende fundamentalmente de las condiciones y políticas vigentes en los países receptores. En consecuencia, el diseño de políticas en esta materia no debe fundarse en posiciones incondicionalmente (e ideológicamente) amigables $\mathrm{u}$ hostiles hacia la IED, sino en la necesidad de aprovechar los resultados de las experiencias pasadas para diseñar instrumentos y estrategias tendientes a maximizar la contribución de la IED al proceso de desarrollo económico de los países del Mercosur y evitar sus posibles consecuencias adversas.
Aitken, B. y A. Harrison (1999): Do domestic firms benefit from direct foreign investment? Evidence from Venezuela, American Economic Review, vol. 89, № 3, Nashville, Tennessee, American Economic Association, junio.

Aitken, B., G. Hanson y A. Harrison (1997): Spillovers, foreign investment, and export behavior, Journal of International Economics, vol. 43, № 1-2, Amsterdam, Elsevier.

Alvarez, R. (2005): Explaining Export Success in a Developing Country: Firm Characteristics and Spillover Effects, documento de trabajo, Los Ángeles, California, UCLA Anderson School of Management.

Barba Navaretti, G. y A. J. Venables (2004): Multinational Firms in the World Economy, Princeton, Princeton University Press.

Barrios, S., H. Görg y E. Strobl (2003): Explaining firms' export behaviour: R\&D, spillovers and the destination market, Oxford Bulletin of Economics and Statistics, vol. 65, N ${ }^{\circ}$, Oxford, Reino Unido, Blackwell Publishing.

Basu, P., C. Chakraborty y D. Reagle (2003): Liberalization, FDI, and growth in developing countries: a panel co-integration approach, Economic Inquiry, vol. 41, $\mathrm{N}^{\circ} 3$, Oxford, Oxford University Press.

Bittencourt, G. y R. Domingo (2006): Efectos de los derrames de las empresas transnacionales en la industria manufacturera uruguaya (1990-2000), en M. Laplane (coord.), El desarrollo industrial del MERCOSUR: ¿qué impacto han tenido las empresas extranjeras?, Buenos Aires, Siglo Veintiuno Editora Iberoamericana.

Bittencourt, G., R. Domingo y N. Reig (2006a): Efectos de derrame de las ET sobre el comercio exterior de la industria manufacturera uruguaya 1990-2000, Montevideo, Departamento de Economía (DECON)/Universidad de la República (UDELAR), inédito.

(2006b): IED y crecimiento económico de largo plazo en el MERCOSUR, Montevideo, Departamento de Economía (DECON)/ Universidad de la República (UDELAR), inédito.

Blalock, G. y P. Gertler (2005): Foreign direct investment and externalities: the case for public intervention, en T. Moran, E. Graham y M. Blomstrom (comps.), Does Foreign Direct Investment Promote Development?, Washington, D.C., Instituto de Economía Internacional.

Blonigen, B. y M. Wang (2005): Inappropriate pooling of wealthy and poor countries in empirical FDI studies, en T. Moran, E. Graham y M. Blomstrom (comps.), Does Foreign Direct Investment Promote Development?, Washington, D.C., Instituto de Economía Internacional.

Borenztein, E., J. de Gregorio y J.W. Lee (1998): How does foreign direct investment affect economic growth?, Journal of International Economics, vol. 45, No 1, Amsterdam, Elsevier.
Calderón, C., N. Loayza y L. Serven (2004): Greenfield Foreign Direct Investment and Mergers and Acquisitions: Feedback and Macroeconomic Effects, Policy Research Working Paper Series, No 3192, Washington, D.C., Banco Mundial.

Carkovic, M. y R. Levine (2005): Does foreign direct investment accelerate economic growth?, en T. Moran, E. Graham y M. Blomstrom (comps.), Does Foreign Direct Investment Promote Development?, Washington, D.C., Instituto de Economía Internacional.

CEPAL (Comisión Económica para América Latina y el Caribe) (2000): La inversión extranjera en América Latina y el Caribe. Informe 1999, LC/G.2061-P, Santiago de Chile, enero. Publicación de las Naciones Unidas, $\mathrm{N}^{\mathrm{o}}$ de venta: S.00.II.G.4.

(2006): La inversión extranjera en América Latina y el Caribe, 2005, LC/G.2309-P, Santiago de Chile. Publicación de las Naciones Unidas, $N^{\circ}$ de venta: S.06.II.G.44.

Choe, J. (2003): Do foreign direct investment and gross domestic investment promote economic growth?, Review of Development Economics, vol. 7, $\mathrm{N}^{\mathrm{o}}$ 1, Oxford, Reino Unido, Blackwell Publishing.

Chowdhury, A. y G. Mavrotas (2005): FDI and Growth: A Causal Relationship, Research Paper, $\mathrm{N}^{\circ}$ 25, Ginebra, Instituto Mundial de Investigaciones de Economía del Desarrollo/Universidad de las Naciones Unidas.

Chudnovsky, D. y A. López (2001): La inversión extranjera directa en el MERCOSUR. Un análisis comparativo, en D. Chudnovsky (coord), El boom de inversión extranjera directa en el MERCOSUR, Madrid, Siglo Veintiuno.

(coords.) (2002): Integración regional e inversión extranjera directa: el caso del MERCOSUR, Buenos Aires, Instituto para la Integración de América Latina y el Caribe.

Chudnovsky, D., A. López y E. Orlicki (2006): Impact of Foreign Direct Investment on Employment, Productivity, Trade, Innovation, Wage Inequality and Poverty: A study of Argentina 1992-2001, Final Report, Washington, D.C., Global Development Network.

Chudnovsky, D., A. López y G. Pupato (2006): Innovation and productivity in developing countries: a study of Argentine manufacturing firms' behavior, Research Policy, vol. 35, $\mathrm{N}^{\circ} 2$, Amsterdam, Elsevier, marzo.

Chudnovsky, D., A. López y G. Rossi (2006): Derrames de la inversión extranjera directa, políticas públicas y capacidades de absorción de las firmas nacionales del sector manufacturero argentino (1992-2001), en M. Laplane (coord.), El desarrollo industrial del MERCOSUR: ¿qué impacto han tenido las empresas extranjeras?, Buenos Aires, Siglo Veintiuno Editora Iberoamericana. 
Cuadros, A., V. Orts y M. Alguacil (2004): Openness and growth: reexamining foreign direct investment, trade and output linkages in Latin America, Journal of Development Studies, vol. 40, $\mathrm{N}^{\circ} 4$, Londres, Routledge, abril.

De Negri, F. (2003): Desempenho comercial das empresas estrangeiras no Brasil na década de 90, tesis de doctorado, Campinas, Instituto de Economía, Universidad Estadual de Campinas (UNICAMP).

Dias de Araújo, R. (2005): Esforços tecnológicos das firmas transnacionais e domésticas, en J.A. de Negri y M. Salerno, Inovações, padrões tecnológicos e desempenho das firmas industriais brasileiras, Brasilia, Instituto de Investigación Económica Aplicada (IPEA).

Erdilek, A. (2005): R\&D activities of foreign and national establishments in Turkish manufacturing, en T. Moran, E. Graham y M. Blomstrom (comps.), Does Foreign Direct Investment Promote Development?, Washington, D.C., Instituto de Economía Internacional.

Görg, H. y D. Greenaway (2004): Much ado about nothing? Do domestic firms really benefit from foreign direct investment?, The World Bank Research Observer, vol. 19, No 2, Oxford, Oxford University Press.

Greenaway, D., N. Sousa y K. Wakelin (2004): Do domestic firms learn to export from multinationals?, European Journal of Political Economy, vol. 20, № 4, Amsterdam, Elsevier

Hiratuka, C. y F. de Negri (2004): Influencia del origen del capital sobre los patrones del comercio exterior brasileño, Revista de la CEPAL, $\mathrm{N}^{\circ}$ 82, LC/L.2220-P, Santiago de Chile, Comisión Económica para América Latina y el Caribe (CEPAL), abril.

Hiratuka, C. y R. Dias de Araújo (2006): Influencia da presença de firmas transnacionais sobre as exportaçoes das firmas domésticas, Campinas, Núcleo de Economia da Indústria e da Tecnologia (NEIT)/Universidad Estadual de Campinas (UNICAMP), inédito.

Hiratuka, C. y R. Sabatini (2006): Avaliação das mudanzas recentes na cupula empresarial no MERCOSUR, Campinas, Núcleo de Economia da Indústria e da Tecnologia (NEIT)/Universidad Estadual de Campinas (UNICAMP), inédito.

Javorcik, B.S. (2004): Does foreign direct investment increase the productivity of foreign firms? In search of spillovers through backward linkages, American Economic Review, vol. 94, № 3, Nashville, Tennessee, American Economic Association.

Jefferson, G., B. Huamao y otros (2002): R\&D performance in Chinese industry, inédito.

Kneller, R. y M. Pisu (2004): Export oriented FDI in the UK, Oxford Review of Economic Policy, vol. 20, $\mathrm{N}^{\mathrm{o}} 3$, Oxford, Oxford University Press.

Kokko, A., M. Zejan y R. Tansini (2001): Trade regimes and spillover effects of FDI: evidence from Uruguay, Weltwirtschaftiliches Archiv, vol. 137, Kiel, Kiel Institute.
Kugler, M. (2001): The Diffusion of Externalities from Foreign Direct Investment: Theory Ahead of Measurement, Discussion Paper Series in Economics and Econometrics, $\mathrm{N}^{\circ} 23$, Southampton, Reino Unido, University of Southampton.

Kumar, N. y A. Aggarwal (2000): Liberalisation, outward orientation and in-house R\&D activity of multinational and local firms: a quantitative exploration for Indian manufacturing, en S. Tendulkar, A. Mitra y otros (comps.), India: Industrialisation in a Reforming Economy, Nueva Delhi, Academic Foundation.

Laplane, M. (coord.) (2006): El desarrollo industrial del MERCOSUR: ¿qué impacto han tenido las empresas extranjeras?, Buenos Aires, Siglo Veintiuno Editora Iberoamericana.

Laplane, M., J. Padovani Gonçalves y R. Dias de Araújo (2006): Efeitos de transbordamento de empresas estrangeiras na indústria brasileira (1997-2000), en M. Laplane (coord.), El desarrollo industrial del MERCOSUR: ¿qué impacto han tenido las empresas extranjeras?, Buenos Aires, Siglo Veintiuno Editora Iberoamericana.

Lipsey, R. y F. Sjoholm (2005): The impact of inward FDI on host countries: why such different answers?, en T. Moran, E. Graham y M. Blomstrom (comps.), Does Foreign Direct Investment Promote Development?, Washington, D.C., Instituto de Economía Internacional.

Mencinger, J. (2003): Does foreign direct investment always enhance economic growth?, Kyklos, vol. 56, № 4, Oxford, Reino Unido, Blackwell Publishing.

Pinheiro, A. y M. Moreira (2000): The Profile of Brazil's Manufacturing Exporters in the Nineties: What are the Main Policy Issues?, Rio de Janeiro, Banco Nacional de Desarrollo Económico y Social (BNDES).

Roper, S. y J. Love (2001): The Determinants of Export Performance: Panel Data Evidence for Irish Manufacturing Plants, Working Paper, $N^{\circ} 69$, Belfast, Northern Ireland Economic Research Centre (NIERC).

Srholec, M. (2005): Innovation activities of foreign affiliates in the Czech Republic, documento presentado en la UNCTAD Expert Meeting on the Impact of FDI on Development (Ginebra, 24 al 26 de enero).

UNCTAD (Conferencia de las Naciones Unidas sobre Comercio y Desarrollo) (2005): World Investment Report, 2005: Transnational Corporations and the Internationalization of $R \& D$, UNCTAD/ WIR/2005, Ginebra, Naciones Unidas. Publicación de las Naciones Unidas, $\mathrm{N}^{\circ}$ de venta: E.05.II.D.10.

Zhan, K. (2001): Does foreign direct investment promote economic growth? Evidence from East Asia and Latin America, Contemporary Economic Policy, vol. 19, № 2, Oxford, Oxford University Press. 